\title{
Contradições no agir do voluntário nas organizações da sociedade civil: ensaio teórico à luz da sociologia pragmática francesa
}

\author{
TANDARA DIAS GONÇALVES \\ Universidade Regional do Noroeste do Estado do Rio Grande do Sul (UniJuí) / Programa de Pós-Graduação em \\ DESENVOLVIMENTO REGIONAL, IJUÍ - RS, BRASIL
}

DENIZE GRZYBOVSKI

Universidade Regional do noroeste do Estado do Rio Grande do Sul (Uniuuí) / Programa de Pós-Graduação em DESENVOLVIMENTO REGIONAL, IJUÍ - RS, BRASIL

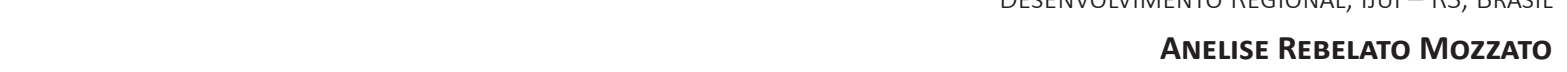

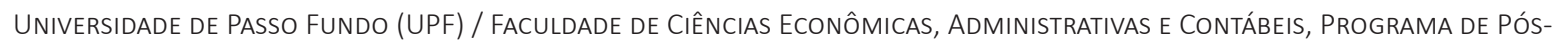
GRAdUAÇÃO EM AdMINISTRAÇÃO, PASSO FUNDO - RS, BRASIL

CARLISA SMOKTUNOWICZ TOEBE Instituto Federal de Educação, Clência e TeCnologia do RIo Grande do Sul (IFRS - CAmpus Sertão), Sertão - RS, BRASIL

\begin{abstract}
Resumo
O voluntariado é um fenômeno social crescente no contexto atual e que se apresenta como alternativa à lógica do capitalismo na gestão das organizações da sociedade civil. Contudo é possível que haja contradições no agir do voluntário, cuja ação humana pode estar sendo mediada por fatores comportamentais subjacentes ao comportamento aparente, nem sempre considerado nobre, como, por exemplo, o egoísmo. O presente ensaio teórico tem como objetivo compreender o que está por trás da ação humana no comportamento do voluntário das organizações da sociedade civil (OSCs), razão pela qual os argumentos teóricos foram construídos pela Sociologia Pragmática, que busca encontrar razões do agir pelas mediações simbólicas, em detrimento da psicologia comportamental. Afirma-se que os voluntários são dotados de comportamento racional e justificável por três regimes pragmáticos desenvolvidos por Laurent Thévenot e pelos conceitos complementares de Frédéric Vandenberghe; ambos defendem que as ações humanas são justificáveis. Os argumentos apresentados confirmam teoricamente que os fatores comportamentais dos voluntários produzem efeitos nos resultados das OSCs, como o seu baixo grau de envolvimento, uma vez que as justificativas do agir podem estar centralizadas nos mundos "da fama" e o "mercantil", contribuindo para gerar inquietações entre os pesquisadores sobre a possível inferência daquilo que está por trás da ação humana.
\end{abstract}

Palavras-chave: Sociologia Pragmática francesa. Fatores comportamentais. Voluntariado. Organizações da sociedade civil (OSCS). Ensaio teórico.

Contradictions in the action of the volunteer in civil society organizations: theoretical essay in the light of French pragmatic sociology

\section{Abstract}

Volunteering is a growing social phenomenon in the current context and is presented as an alternative to the logic of capitalism in the management of civil society organizations. However, it is possible that there are contradictions in the action of the volunteer, whose human action may be mediated by behavioral factors underlying apparent behavior, not always considered noble, such as egoism. This theoretical essay aims to understand what is behind human action in the behavior of volunteers of civil society organizations (CSOs). Therefore, the theoretical arguments were built by pragmatic sociology, which seeks to find reasons for acting through symbolic mediations, to the detriment of behavioral psychology. It is argued that volunteers are endowed with rational and justifiable behavior by three pragmatic regimes developed by Laurent Thévenot and by the complementary concepts of Frédéric Vandenberghe; both argue that human actions are justifiable. The arguments presented theoretically, confirm that the behavioral factors of the volunteers, produce effects on the results of the CSOs. These effects include the low degree of involvement of the volunteers with the organizations, since the justifications for acting can be centered on world such as "fame" and "mercantile", contributing to generate uneasiness among researchers about the possible inference of what lies behind human action.

Keywords: French Pragmatic sociology. Behavioral factors. Volunteers. Civil society organizations. Theoretical essay.

\section{Contradicciones en el actuar del voluntario en las organizaciones de la sociedad civil: ensayo teórico a la luz de} la sociología pragmática francesa

\section{Resumen}

El voluntariado es un fenómeno social creciente en el contexto actual y que se presenta como alternativa a la lógica del capitalismo en la gestión de las organizaciones de la sociedad civil. Sin embargo, es posible que haya contradicciones en el actuar del voluntario, cuya acción humana podría ser mediada por factores conductuales subyacentes al comportamiento aparente, no siempre considerados nobles, como el egoísmo. El presente ensayo teórico tiene como objetivo comprender lo que está detrás de la acción humana en el comportamiento del voluntario de las organizaciones de la sociedad civil (OSC), razón por la cual los argumentos teóricos fueron construidos por la sociología pragmática, que busca encontrar las razones del actuar por las mediaciones simbólicas, en detrimento de la psicología conductual. Se afirma que los voluntarios están dotados de comportamiento racional y justificable por tres regímenes pragmáticos desarrollados por Laurent Thévenot y por los conceptos complementarios de Frédéric Vandenberghe; ambos defienden que las acciones humanas son justificables. Los argumentos presentados confirman teóricamente que los factores conductuales de los voluntarios producen efectos en los resultados de las OSC, como el bajo grado de implicación de estos, ya que las justificaciones del actuar pueden estar centralizadas en los mundos de la "fama” y "mercantil", lo que contribuye a generar inquietudes entre los investigadores sobre la posible inferencia de lo que está detrás de la acción humana.

Palabras clave: Sociología pragmática francesa. Factores de comportamiento. Voluntariado. Organizaciones de la sociedad civil (OSC). Ensayo teórico. 


\section{INTRODUÇÃO}

O tema central deste ensaio teórico são os fatores comportamentais dos voluntários nas organizações da sociedade civil (OCSs) à luz da Escola Francesa da Sociologia Pragmática (KARAM e SERVA, 2014). Este tema desperta interesse científico em razão do notável crescimento no número destas organizações no contexto brasileiro (IBGE, 2012; ONU BRASIL, 2017) e do interesse percebido em membros da sociedade no sentido de auxiliar aqueles mais necessitados, marginalizados, drogaditos e outros (CHARITIES, 2012). No entanto, nem sempre o fenômeno voluntariado nestas organizações é pautado pelo amor ao próximo e pelo interesse pessoal e espírito cívico, que leva a dedicar parte do próprio tempo a atividades de bem-estar social (ONU BRASIL, 2017).

Por voluntário entende-se toda pessoa que doa seu trabalho e suas competências por razões de natureza social, para que lhe proporcione um sentimento de gratificação pela realização. $O$ voluntário realiza uma ação social definida com base na qualificação profissional, satisfação, doação e realização pessoal, trata-se de uma ação de qualidade que faz a diferença numa determinada comunidade; não precisa ser grande, mas eficiente.

A abordagem teórica da Sociologia Pragmática traz a representatividade de uma teoria da ação, colocando as práticas constituintes da situação no centro da análise. A opção pela vertente teórica da escola francesa permite estudar, no nível analítico e individual, os fatores comportamentais dos indivíduos tendo por base sua caracterização e suas razões para agir. No desenvolvimento do presente estudo, partiu-se do pressuposto teórico de que os voluntários nas organizações da sociedade civil direcionam suas escolhas para realizar ações voluntárias orientando-se por fatores comportamentais descritos como comportamento egoísta e subjacente (MOSCOVICl, 2012) à ação social, que encontra nos impulsos e desejos inconscientes reprimidos sua expressão real, como pressupõe a perspectiva teórica freudiana (FREUD, 1974).

A discussão sobre os fatores comportamentais dos voluntariados nas OSCs parte da origem da motivação em realizar ações voluntárias pela concepção ideológica de ser uma pessoa melhor (TENÓRIO, 2004) ou pela herança cultural do Brasil colonial (ANDION, 2007). Também pode ser um tipo de controle (emocional, econômico, moral...) exercido pela cultura organizacional sobre os voluntários (MORGAN, 2013). Assim, as questões sobre os fatores comportamentais dos voluntários são recolocadas não apenas na perspectiva do indivíduo, mas também na perspectiva do tipo de organização no qual o voluntário exerce o "trabalho voluntário" (DOHME, 2001), pois o sentido do trabalho é o que orienta suas decisões (MORIN, 2001).

Acredita-se que os fatores comportamentais dos voluntários encontram espaço para compreender os comportamentos maquiavélicos em OCSs, em que a função de natureza social proporciona sentimentos de satisfação pela realização. Logo, pergunta-se: quais fatores comportamentais direcionam a escolha das pessoas que assumem a ação voluntária nas organizações da sociedade civil?

Com o objetivo geral de compreender os fatores que influenciam o comportamento dos voluntários na realização da ação social nas OCSs, foi necessário recorrer à Sociologia Pragmática e naõ à Psicologia Comportamental. É na Sociologia Pragmática que se encontram elementos para entender as razões do agir pelas mediações simbólicas, ou seja, o que está por trás da ação humana.

A corrente teórica da Sociologia Pragmática tem como seus precursores Luc Boltanski e Laurent Thévenot, a qual foi iniciada fundamentalmente no livro De la justification: Les èconomies de la grandeur, de 1991. Esta obra será utilizada neste ensaio teórico como principal referência, à qual se somam artigos científicos nela baseados. Nesta obra, os autores explicam as bases da teoria na metodologia de aplicação e como chegam às ordens legítimas (cidades ou mundos; cités). Os referidos mundos correspondem às seis grandes lógicas de justificação, as quais encontram-se ocultas na ação humana (KRIEGER, 2011; KARAM, 2014).

Também se considera fundamental a obra Le nouvel esprit du capitalisme, de Boltanski e Chiapello (2009). Nela os autores reconstituem a história do capitalismo e das justificações coletivas utilizadas para aderir à lógica capitalista, sugerindo e originando uma nova lógica de justificação da ação, uma sétima lógica de justificação acrescida às seis descritas por Krieger (2011).

Assim, na perspectiva da Sociologia Pragmática, os fatores comportamentais dos voluntários podem ser estudados com base em sua caracterização e em suas razões para agir, como propõe Thévenot (2001). Dada a relevância de ações rotineiras ou intensas situações de disputas e conflitos entre atores sociais, a Sociologia Pragmática verte da microssociologia e reconstitui o elo com a macrossociologia por meio das "[...] mediações simbólicas que são as cidades" (VANDENBERGHE, 2006, p.315). 
Desse modo, consideram-se os conceitos de Vandenberghe (2006) e de Thévenot (2001) como complementares, uma vez que ambos defendem na Sociologia Pragmática que as ações humanas são justificáveis. Para esses autores, o comportamento está no centro de análise na teoria dos atos de linguagem e da etnometodologia, discutidas por Jürgen Habermas e John C. Heritage, entre outros. Para Habermas (1999), o ato de fala ou os atos de linguagem dão-se no reconhecimento da "virada pragmática" pela filosofia da linguagem. Tal teoria está interligada à práxis comunicativa e não apenas à representação da realidade, considerando o caráter intersubjetivo da linguagem (sinais linguísticos) ou o caráter pragmático.

De acordo com Heritage (1999), o mundo social é complexo e sua compreensão ocorre por meio dos fenômenos empíricos da atividade social em toda a sua riqueza e diversidade, traduzidas por um sólido programa de investigação empírica, a etnometodologia. Mesmo criticado pela base teórica de Talcott Parsons, Guesser (2003) afirma que Garfinkel reformula a sociologia tradicional pela influência da fenomenologia de Alfred Schütz e Eduard Husserl e revela a natureza da intersubjetividade da ação social. Assim o fazendo, não permite generalização teórica dos dados empíricos, pois a investigação é conduzida em grupos escolhidos por suas particularidades, os quais têm uma identidade revelada pelos elementos presentes na fala apreendida no processo de análise da conversação. Isso significa dizer que o que este grupo faz ou diz no processo de investigação e o que seus integrantes iriam fazer ou dizer em outros contextos podem não refletir a realidade (HERITAGE, 1999; GUESSER, 2003).

Conhecida também como sociologia francesa, dotada de uma abordagem crítica, a Sociologia Pragmática faz contornos nas questões do senso comum e é dedicada a evidenciar a redução da ação ao comportamento individual. Vandenberghe (2006) denuncia que Estado, igreja ou a sociedade realizam ações como pessoas e não como organizações. Por fim, no nível do indivíduo e na perspectiva da Sociologia Pragmática, os voluntários são dotados de comportamento racional e justificável por três linhas teóricas - que se configuram em regimes pragmáticos - encontradas na Sociologia Pragmática (BOLTANSKI e THÉVENOT, 2006; VANDENBERGHE, 2006).

Thévenot (2001) orienta uma nova perspectiva de três questionamentos da Sociologia Pragmática, que até então estão sendo isoladas e estudadas separadamente umas das outras (como afirmam KARAM e SERVA, 2014): (a) a caracterização do agente e suas razões para agir; (b) as modalidades de coordenação das ações; e (c) o papel dos valores e bens comuns. Neste ensaio teórico, o foco do estudo recai sobre a primeira, a caracterização do voluntário e suas ações para agir.

Na mesma direção, Thévenot (2001) contextualiza o regime de justificação, o qual se refere a convenções coletivas em prol do bem comum. $O$ referente regime concerne primeiramente à correlação do ator com ele mesmo, em um ambiente onde o ator deve coordenar sua própria conduta. Sendo assim, cada ação do ator social é explicada pelo regime de justificação, ou seja, primeiro justifica-se a ação para depois concretizá-la.

O estudo se justifica pela originalidade do tema, decorrente de uma área de poucos estudos voltados ao indivíduo como voluntário, e pela escassez de pesquisas sobre as verdadeiras motivações que induzem os voluntários a dedicarem parte de seu tempo e esforço em prol de uma causa social. Tais causas têm sido objeto de ação em OSCs, e são interpretadas como agentes de associativismo voluntário com poder de examinar e transformar estruturas sociais e políticas com as quais promovem interação (KEANE, 1998 apud KRIEGER, 2011). Contudo surgem dúvidas sobre as intenções do agir dos voluntários. Seu agir seria intencional e seu comportamento estimulado por elementos simbólicos ou por fatores comportamentais? Pelos atos da fala, na perspectiva weberiana, a ação social é resultado de um comportamento subjetivo dotado de sentido, ou seja, orientado subjetivamente e motivado por ele, argumenta Habermas (2009).

São apresentados a seguir os resultados dessas reflexões teóricas, que têm por base a definição e compreensão do papel dos voluntários na sociedade contemporânea e seu comportamento em ações de voluntariado. Na sequência, apresenta-se a problemática das motivações dos voluntários em ações de voluntariado.

\section{OS VOLUNTÁRIOS E O COMPORTAMENTO HUMANO EM AÇÕES DE VOLUNTARIADO}

Para Habermas (2009), o que diferencia o homem do animal, o ser social do ser natural, não é propriamente o trabalho, mas sim a linguagem. Somente após a "economia de caça", o trabalho propriamente dito (já encontrado em alguns primatas) é complementado por uma "estrutura social familiar", cujo conjunto é equivalente ao desenvolvimento de normas sociais, sistema que pressupõe linguagem. 
Diante do desafio de analisar a sociedade capitalista, Habermas (2009) desenvolveu uma nova teoria, aparentemente superando as ideias marxistas. Tal teoria teria capacidade de interpretar a nova realidade social e de ainda propor uma nova visão para completar o novo paradigma no qual a "teoria do agir comunicativo" tem a proposta da nova centralidade comunicacional e da intersubjetividade. Nela Habermas (2009) retoma a afirmação de que o sujeito é quem inventa a sociedade civil perante o Estado, evidenciando um processo de subjetivação da identidade de um "eu" que efetivamente se relaciona na dialética do sujeito com o outro, dentro da intersubjetividade. Trata-se do conceito habermasiano de subjetividade: "[...] o homem só adquire consciência de si mesmo através do outro, ao desenvolver uma interação reflexiva, através da linguagem, da ação comunicativa, em relação com e na construção de um mundo objetivo" (HABERMAS, 1990, p. 72). Assim, a sociedade é constituída por estruturas objetivas e subjetivas, sendo que a intersubjetividade é construída por meio da linguagem e de ações realizadas por atores sociais.

Para Machado (1995), "atores sociais" são grupos específicos responsáveis por gerar movimentos; alguns institucionais, como a Igreja Católica, sendo o mais importante no caso do Brasil. Touraine (2011) menciona "atores coletivos" como atores de classes, citando, por exemplo, a classe operária tradicional no pensamento marxista. Tais interpretações remetem à ideia da coletividade numa perspectiva sociológica de grupos sociais, sem contemplar a dimensão intersubjetiva que nela existe, resultado de processo de ação e interesses. Tenório (2004, p. 73) chama a atenção para os processos de ação e interesses, referindo-se a "alianças e parcerias" entre atores sociais e atores coletivos, que têm por característica de funcionamento 0 estabelecimento de elos entre si de forma que os interesses são atendidos de comum acordo.

Nessa lógica pode-se entender o voluntário como resultado do elo entre sociedade civil, Estado e outros atores sociais. Tal elo é considerado necessário à gestão das OSCs para manter a atenção no comportamento humano em ações de voluntariado, uma vez que estas relações formam a sociedade e, por conseguinte, os grupos sociais, numa relação dialética de causa e efeito.

O comportamento humano tem sido objeto de muitos estudos, não apenas por ser uma área de grande abrangência, mas também por ser considerada uma ciência com muitos campos ocultos e profundas teorias. Uma das muitas razões por este interesse deve-se à singularidade da raça humana (HATTORI e YAMAMOTO, 2012).

Kanaane (1994) entende o indivíduo como um ser social, com capacidade de relações sociais, com aspectos facilitadores e impeditivos, como bloqueios e omissões, os quais caracterizam o seu processo de socialização. Este processo direciona as vontades e os valores intrínsecos ao comportamento humano, que se apresentam já na infância e se compõem de normas e valores transmitidos pela família, estabelecendo "[...] funções instrumentais, consumatórias, ajustadoras ou utilitárias, ego-defensivas, expressão de valores, de controle e apropriando-se de fatores condicionantes de uma sociedade" (KANAANE, 1994, p. 43).

Na perspectiva da Psicologia Comportamental, para Freud (1974) a sociedade gerou regulamentos que ordenam a vida de seus integrantes resultando em privação da liberdade comportamental, o que leva os indivíduos a renunciarem a uma suposta liberdade individual em favor do bem resultante da convivência social. O caráter do indivíduo, portanto, é formado pelos valores que circulam na sociedade, oferecendo ao indivíduo a possibilidade de autoafirmação e formação da sua individualidade (KANAANE, 1994). Porém, como salienta Kolb (1977), o ser humano nasce dotado de padrões inscritos e potencialidades, ou seja, um conjunto constituído por padrões e tendências comportamentais, definido pelo termo "personalidade". Derivado da personalidade, Bergeret (1988) faz menção ao termo "caráter", definindo-o como base para a formação do indivíduo e sua maneira de se relacionar, defender-se e adaptar-se às diversas formas de dirigir e tratar suas necessidades, seus conflitos internos, suas angústias e, ainda, o nível de fantasia mental.

A interação social é parte integrante das necessidades humanas. Lewin (1973), criador da Teoria do campo social, pondera que o indivíduo, consciente ou não de suas ações, utiliza um determinado grupo de relações sociais para manter e satisfazer suas necessidades próprias, incluindo suas ambições sociais, usando o grupo como um instrumento. Em sua teoria, o referido autor mostra que, para haver adaptação social, a pessoa deverá superar e atualizar suas ambições e atitudes, atingir seus objetivos pessoais por meio de laços com outros membros do grupo social no qual está inserida.

Schutz (1978) complementa os ensinamentos de Lewin (1973) ao destacar que a inclusão, o controle e o afeto são necessidades interpessoais. A necessidade de inclusão tem o objetivo de manter um bom relacionamento com outras pessoas, resultando em interação e associação. A segunda necessidade, de controle, refere-se à existência de um conforto psicológico em controlar e ser controlado, sendo uma ligação ao sentimento de respeito mútuo pelo merecimento de ser respeitado. E, por 
fim, a necessidade de afeição é estabelecida na conservação de relacionamentos satisfatórios com outras pessoas no que tange ao amor e à afeição.

Ao reconhecer o ser humano como um ser social e com necessidade de relacionamentos, abre-se espaço para correlacionar os fatores comportamentais dos voluntários às necessidades humanas básicas, em especial a de autorrealização. O suposto voluntariado não representa efetivamente um ato voluntário na perspectiva da justiça social, mas uma ação social movida por interesses pessoais, conscientes ou não, cujas categorias analíticas são egoísmo, intenções e interesses.

A categoria egoísmo é formada pelo egoísmo psicológico e egoísmo ético. O egoísmo psicológico representa o agir de forma a se beneficiar, enquanto o egoísmo ético representa o agir visando ao seu próprio bem-estar. O egoísmo ético preza pela segurança/responsabilidades/solução das necessidades fundamentais de um indivíduo, o que não o isenta de ser egoísta (CONSTANTINO, 2007). O interesse, por sua vez, é considerado um processo cognitivo capaz de gerar emoções que interagem no sujeito-ambiente, ações para satisfazer as necessidades humanas e preservar os valores individuais e/ou coletivos e, ao mesmo tempo, promover o desenvolvimento pessoal e consolidar a identidade do ator social. Já as intenções são um conjunto de variáveis do comportamento humano demandadas pelo ambiente. Derivam das experiências vividas pelos atores sociais e, por isso, são relativas ao contexto ao qual o ator social pertence. Dessa forma, afirma-se que todo comportamento humano é planejado com base nas intenções do indivíduo, produzidas por motivos específicos.

Em síntese, as três categorias analíticas do comportamento dos voluntários (egoísmo, interesses e intenções) atuam no direcionamento das ações de voluntariado, num processo dinâmico e interativo relacionado a outras questões do comportamento humano, que contemplam os fatores sociais, psíquicos e emocionais num nível macro de análise. Como orientadores do comportamento, no nível micro, atuam nos sentidos do trabalho atribuídos por cada voluntário; e no altruísmo egoísta, descrito por Hobbes (2012), pela caridade e piedade. Assim se insere a problemática das motivações dos voluntários na realização de atividades voluntárias em organizações da sociedade civil.

\section{A PROBLEMÁTICA DAS MOTIVAÇÕES DOS VOLUNTÁRIOS}

Uma das principais características das OSCs é a sua composição: é formada por agentes solidários, comumente chamados de voluntários (TENÓRIO, 2004; ESCOBAR e GUTIÉRREZ, 2008). Pressupõe-se que, entre os voluntários brasileiros que atuam em OSCs, o comportamento subjacente (MOSCOVICI, 2012) seja o orientador das ações de voluntariado. A justificativa para tanto é de que as características racionais são uma expressão real de impulsos e desejos inconscientes nas pessoas que atuam nas OSCs, o que encontra respaldo nas análises de Moscovici (2012) sobre comportamento humano.

Quanto ao comportamento humano e seus fenômenos, Moscovici (2012) afirma que suas origens e explicações estão no inconsciente, determinante da maioria das ações aparentemente inexplicáveis por outras teorias. Inconsciente, para Freud (1974), é um depósito de desejos e impulsos reprimidos pela pessoa, o qual é necessário para a sua construção familiar e social.

A orientação de Freud (1974) é de que, na civilização, as pessoas agem sob coerção e renunciando a instintos; se, em hipótese, houvesse a interrupção da coerção, a maioria dos seres humanos estaria preparada para empreender o trabalho necessário à aquisição de novas riquezas. Para tanto, deve-se considerar o fato de tendências destrutivas estarem presentes em todos os humanos e, portanto, antissociais e anticulturais, e que, em um grande número de pessoas, essas tendências são suficientemente fortes para determinar seu comportamento na sociedade. Nessa abordagem, pode-se perceber que Freud (1974) descreve o comportamento humano por uma perspectiva teórica antipositivista, ou seja, as pessoas agem por razões que estão no inconsciente.

A discussão sobre os fatores comportamentais dos voluntariados nas OSCs parte da motivação de um indivíduo em realizar trabalhos voluntários, que pode ser pela concepção ideológica de ser uma pessoa melhor (TENÓRIO, 2004) ou por herança cultural, remontando à época do Brasil colonial (ANDION, 2007). Outra possibilidade, como Morgan (2013) defende numa das propostas principais da cultura organizacional, é de que este indivíduo poderá exercer algum tipo de controle (emocional, econômico, moral...) sobre os demais voluntários.

Foucault (2012) trata esse tipo de controle pela perspectiva do poder, como identificação de sujeitos atuando sobre outros sujeitos. Referindo-se a poder, direito e verdade, o autor criou um triângulo que demonstra o poder como direito, por meio 
das formas como a sociedade se coloca e se movimenta, ou seja, onde há rei, há súditos. O autor argumenta ainda que o poder usado por alguém como verdade tem sua origem nos movimentos da sociedade, dos quais os indivíduos tornam-se vítimas, geralmente sem consciência e reflexão, ou seja, em uma mera reprodução de atos mecânicos produzidos pela própria sociedade, organizada ou não.

Maquiavel (1999), com seu olhar cético sobre o ser humano, assimila a concepção de poder acima da ética, o que lhe levou a propugnar a máxima de que os fins justificam os meios. Tudo é válido desde que o objetivo seja manter-se com poder. De acordo com esse pensamento, é possível que voluntários busquem realizar-se na "ação social", no sentido descrito por Dohme (2001), mas acabam por fazê-lo em busca de poder, na perspectiva foucaultiana.

Por sua vez, Gaulejac (2007) trata o poder como um novo controle que surgiu nas relações gerenciais do modelo capitalista e dominador; é um poder de difícil contestação, pois as contraposições refletem-se em nível psicológico nas vítimas por meio de insegurança, sofrimento psíquico, esgotamento profissional, perturbação psicossomática e depressões nervosas. O autor sugere uma forma de recuperação do sentido de vida, usando como valor a solidariedade e o respeito ao próximo e à natureza, baseando-se em princípios do oikos logos - ecologia e desenvolvimento durável -, princípios do antrophos logos espécie humana e sociedade -, e nos princípios da psyché logos - vida psíquica humana. Assim, as questões sobre os fatores comportamentais dos voluntários são recolocadas não apenas na perspectiva do indivíduo, mas também no tipo de organização na qual o voluntário realiza a ação de voluntariado (DOHME, 2001).

A definição do tipo organizacional da sociedade civil também é um ponto de debate na literatura atual. Até então conhecidas como organizações do terceiro setor, a denominação de OSCs na identificação de organizações que usam voluntários para realizar ações na sociedade ainda é pouco conhecida.

Há forte crítica à existência do chamado terceiro setor e suas organizações (SARAIVA, 2006). Para Montaño (2005), o terceiro setor é uma lacuna entre Estado e mercado, indicando a contraposição destes dois setores à sociedade civil. Em uma perspectiva crítica, tal termo é inadequado ao real e carregado de ideologia, pois a realidade social não pode ser dividida em "primeiro", "segundo" e "terceiro" setor, tendo fundamentação num conceito abstrato, sem existência real. No entanto, não se deve fechar os olhos às atividades da sociedade civil, que efetivamente vêm desenvolvendo atividades antes atribuídas ao Estado. A sociedade civil organizada é dotada de responsabilidade na busca de resposta às necessidades dos indivíduos marginalizados, é formada por atores sociais, cidadãos, e voltada para uma suposta sociedade mais justa e digna (MONTAÑO, 2005).

Acredita-se, portanto, que os fatores comportamentais dos voluntários em OSCs são encontrados em organizações construídas no modelo capitalista, nas quais há espaço para comportamentos maquiavélicos, e também em organizações dotadas de responsabilidade em construir uma sociedade mais justa e digna, como afirma Montaño (2005), cuja função de natureza social proporcione sentimento de satisfação pela realização, como sugere Dohme (2001).

Nessa lógica, a problemática encontra respaldo na perspectiva da Sociologia Pragmática (sociologia francesa). Assim, tendo por base esta orientação teórica, espera-se acessar e mapear os fatores comportamentais dos voluntários por meio dos regimes pragmáticos desenvolvidos por Thévenot (2001), quais sejam: familiaridade, ação planejada e regime de justificação.

Neste estudo, as organizações da sociedade civil serão discutidas pela perspectiva de Tenório (2013, n/d):

A sociedade exige que os atores que a compõem, o Estado, o sistema empresarial privado e a sociedade civil organizada, assim como o cidadão de uma maneira geral, interatuem através de processos de tomada de decisão que, a partir de conquistas ou patologias do passado, permitam a sustentabilidade ambiental, cultural, econômica e política, presente e futura.

Nesse contexto encontram-se todas aquelas organizações que propõem debates sobre questões de cidadania e políticas públicas à margem do Estado. Ao construir um conceito desse tipo organizacional, Tenório (2001), demonstrando uma visão conservadora, cuidadosamente refere-se ao terceiro setor como formado por organizações que não fazem parte do Estado, nem a ele são vinculadas; são revestidas de caráter público na medida em que se dedicam a causas e problemas sociais e em que, apesar de caracterizarem sociedades civis privadas, não têm por objetivo o lucro e sim o atendimento das necessidades da sociedade.

Logo, questiona-se: quais fatores direcionam a escolha comportamental das pessoas que assumem o trabalho voluntário nas organizações da sociedade civil organizada e que contribuição tais fatores exercem na definição do seu perfil? Entende-se que a Sociologia Pragmática traz contribuições na tentativa de buscar respostas nesse sentido. 


\section{CONTRIBUIÇÃO DA SOCIOLOGIA PRAGMÁTICA, COM BASE EM KARAM E SERVA (2014)}

A Sociologia Pragmática é também denominada "sociologia das provas" (BARTHE, RÉMY, TROM et al, 2016), economia das grandezas, sociologia da crítica, teoria da capacidade crítica, teoria das grandezas e, ainda, escola ou economia das convenções. Os resultados desses estudos constituem parte da escola francesa de sociologia (KARAM e SERVA, 2014; BARTHE, RÉMY, TROM et al, 2016; CORREA e DIAS, 2016).

Essa vertente teórica traz a representatividade de uma teoria da ação, colocando as práticas constitutivas da situação no centro da análise. Tal teoria situa-se epistemologicamente entre a hermenêutica e a fenomenologia, o pragmatismo e o interacionismo simbólico, a teoria dos atos de linguagem e a etnometodologia (VANDENBERGHE, 2006).

No entendimento de Krieger (2011) e Correa e Dias (2016), a Sociologia Pragmática representa um dos polos da "nova guinada" na sociologia francesa, momento em que Luc Boltanski e Laurent Thévenot modificam o enfoque sobre o acordo social. Por isso, cronologicamente, encontra-se no período pós-sociologia crítica de Pierre Bourdieu, como uma busca dos princípios e valores que dão sentido à ação (CORREA e DIAS, 2016).

Segundo Vandenberghe (2006, p. 329 e 330), a Sociologia Pragmática:

[...] rompe com o 'paradigma do desvelamento' dos mestres da suspeição (Marx, Nietzsche, Freud) para se ligar ao paradigma da interpretação dos hermeneutas e dos fenomenólogos, recusando invocar os mecanismos sociais e as forças inconscientes que determinariam o ator, sem ele saber, e explicariam suas ações. A sociologia da justificação apreende o ser humano como um ser livre (als freihandelndes Wesen) e religa o ponto de vista da antropologia pragmática de Kant, insistindo mais sobre o que o ser humano faz do que sobre o que é feito dele.

Silber (2003) afirma que uma característica essencial da Sociologia Pragmática seria sua atenção voltada à falta peculiar de acordos duradouros, o que levaria os indivíduos à necessidade de autojustificação e de críticas, participando de ações rotineiras ou de situações intensas de disputas e conflitos (KRIEGER, 2011; KARAM, 2014).

Com base nas abordagens objetivistas e clássicas da sociologia, os atores sociais são compreendidos como "desprovidos de juízo mental" e não como atores com capacidade de reflexão e discernimento. A sociologia pragmática recusa a ideia separatória do ponto de vista objetivista do cientista social e a perspectiva descuidada dos atores sociais (VANDENBERGHE, 2006). Ela vê os atores com capacidade de reflexão e, também, de afastamento da realidade a fim de desenvolver um pensamento crítico sobre aquele universo no qual está inserido. Tal capacidade deve ser levada em consideração se o objetivo for compreender o modo como os membros da sociedade questionam e criticam instituições, entram em discussões ou se concentram para um acordo (THEVÉNOT, 1998).

Boltanski e Thévenot (2006) explicam um modelo teórico de investigação sobre a maneira como os atores sociais justificam suas ações, dando destaque a disputas, desacordos e, ainda, acordos cotidianos da sociedade. Orientado pelo princípio dialético de construção do conhecimento científico, em dado instante que os atores apresentam críticas e defendem uma posição específica, surgem as controvérsias, disputas e possíveis desacordos, os quais, quando superados, originam acordos de práticas sociais.

No centro da Sociologia Pragmática está um modelo de análise dos regimes, o qual é formado pelos regimes de familiaridade, de ação planejada e o de justificação. Proposto por Thévenot (2001), o referido modelo foi dividido em três hélices explicativas, as quais foram sistematizadas por Karam e Serva (2014) da seguinte forma:

a) o indivíduo é definido pelos regimes pragmáticos que consolidam suas relações com seu ambiente humano e material, desde a dimensão mais profunda até a mais pública de legitimação;

b) a coordenação do método da ação resulta em uma racionalidade "interpretativa", além da "calculativa", para responder à perspectiva do enredamento;

c) a observação do papel dos valores sociais e outras noções de bem comum, na coordenação da ação, não podem reduzir-se a prioridades individuais e sim deverá fornecer um quadro analítico para convergir os legítimos compromissos.

As ações justificáveis são o centro de análise para Boltanski e Thévenot (2006). Os autores defendem que as pessoas não inventam pretextos falsos para ações, mas o contrário, elas legitimam suas ações por meio do teste de justificação. Portanto 
processos violentos e tirânicos não estão no centro dos estudos da Sociologia Pragmática, uma vez que, para esta veia teórica, neste caso, não há justificação (BOLTANSKI e THÉVENOT, 2006; KARAM, 2014).

Boltanski e Thévenot (2006), com intenção de explicar a maneira como os humanos realizam acordos e justificam suas ações, conseguem ir além da divisão clássica entre a "[...] sociologia do fenômeno coletivo (na qual se inscreve a corrente institucional abordada no capítulo precedente) e a lógica da economia neoclássica (na qual se inscreve a corrente estratégica abordada anteriormente)" (KRIEGER, 2011, p. 63). Boltanski e Thévenot (2006) acreditam que o reducionismo aplicado às duas leituras citadas modificam o significado da regra adotada para atingir acordos e o modo dessa construção relaciona-se diretamente às pessoas particulares e não às ações.

Para os autores supracitados, todos os indivíduos convivem sob a autoridade da justificação, ou seja, para haver a edificação de acordos entre os indivíduos, eles devem justificar suas escolhas e ações, legitimando o acordo. Esse imperativo de justificação concerne à possibilidade de coordenação do estado comportamental humano, e essa chamada coordenação é considerada o primeiro pilar da legitimidade. Entende-se então a legitimidade como um fenômeno construído e originado na interseção desses dois movimentos que se influenciam reciprocamente: o dos atores (indivíduos, organizações, seus stakeholders, e aqui, se pode considerar os voluntários) e o da estrutura (regras, valores e crenças da sociedade) (BOLTANSKI e THÉVENOT, 2006; KRIEGER, 2011; KARAM, 2014).

O foco central das pesquisas são os acordos em situações controversas, destacando as habilidades do ser humano em construir associações e, ainda, de entrar em acordos com base em generalidades (BOLTANSKI e THÉVENOT, 2006). Quando os atores sociais não alcançam um consenso, buscam entendimento sobre as condições em que a decisão será tomada, o que eleva a um acesso de "princípio comum" determinando as relações de equivalência. Tal processo de busca pelo princípio comum é infinito, do contrário, a procura por um único princípio transforma tais disputas em uma generalidade. (BOLTANSKI e THÉVENOT, 2006; KARAM, 2014).

Os indivíduos justificam-se por meio de fontes finitas. Boltanski e Thévenot (2006) pressupõem que as justificações são provenientes de lugares comuns (commonplaces) ou princípios superiores comuns, os quais integram ordens legítimas, chamadas de cidades ou mundos (cités). Na elaboração das cidades, os autores valeram-se de obras canônicas selecionadas para ilustrá-las como corpos de regras prescritivas. Tais ilustrações foram sistematizadas por Krieger (2011) em um quadro explicativo conceitual, como consta no Quadro 1, posteriormente adaptado por Karam (2014).

\section{Quadro 1}

\section{Cidades Ilustrando os Regimes de Justificação}

\begin{tabular}{|l|l|}
\hline \multicolumn{1}{|c|}{$\begin{array}{c}\text { Cidades } \\
\text { Cités }\end{array}$} & \multicolumn{1}{c|}{ Descrição } \\
\hline $\begin{array}{l}\text { Cidade } \\
\text { Inspirada }\end{array}$ & $\begin{array}{l}\text { Baseada na obra A cidade de Deus, de Santo Agostinho, tem como princípio superior comum a inspiração do } \\
\text { indivíduo, e a grandeza é demonstrada por aquilo que é inexpressível, maravilhoso, excitante. A grandeza pode ser } \\
\text { acessada quando os indivíduos se liberam de seus laços, hábitos, bens e daquilo que é mundano, e eles o fazem pela } \\
\text { necessidade de criação, pela paixão irracional e espontaneidade. A queda acontece quando o indivíduo deseja voltar } \\
\text { a seus hábitos, ficando paralisado artisticamente. }\end{array}$ \\
\hline $\begin{array}{l}\text { Cidade } \\
\text { Doméstica }\end{array}$ & $\begin{array}{l}\text { Baseada na obra A política extraída das próprias palavras da Sagrada Escritura, de Bossuet, seu princípio superior } \\
\text { comum é a hierarquia e a tradição familiares. A grandeza é expressa por aquilo que é hierarquicamente superior, } \\
\text { bem-criado, sábio e com bons valores, e ela se estende aos seres hierarquicamente inferiores, sendo o superior } \\
\text { é responsável pelos inferiores. O comportamento apropriado, bons hábitos, regras de etiqueta são apreciados } \\
\text { e engrandecem quando colocados em respeito à autoridade e sobre o egoísmo. A queda nesta cidade acontece } \\
\text { quando o indivíduo não consegue manter sua boa educação e suas maneiras; deixa assim de ser digno de respeito. }\end{array}$ \\
\hline $\begin{array}{l}\text { Cidade da } \\
\text { Fama }\end{array}$ & $\begin{array}{l}\text { Baseada na obra O leviatã, de Hobbes, seu princípio superior comum é a opinião pública e a grandeza é a fama, } \\
\text { a reputação, a visibilidade e o sucesso, que são acessados pelo desejo de ser reconhecido e pelo amor próprio. } \\
\text { Para atingir a grandeza, o indivíduo deve estar disposto a abrir mão de seus segredos e a revelar sua vida em } \\
\text { jornais, mensagens, campanhas, entrevistas, etc. As relações entre os indivíduos são baseadas em persuasão, } \\
\text { influências e conhecimentos. A cidade entra em queda quando há indiferença entre os seres, banalidade e falta de } \\
\text { reconhecimento. }\end{array}$ \\
\hline
\end{tabular}




\begin{tabular}{|c|c|}
\hline $\begin{array}{c}\text { Cidades } \\
\text { Cités }\end{array}$ & Descrição \\
\hline Cidade Cívica & $\begin{array}{l}\text { Inspira-se na obra O contrato social, de Rousseau. O princípio superior comum é o bem público, a vontade geral, } \\
\text { o coletivo. A grandeza é a representatividade, a regra, a legalidade, aquilo que é oficial. Ela é acessada pela } \\
\text { vontade comum de alcançar os direitos civis e a participação. Para isso, o indivíduo deve renunciar àquilo que é } \\
\text { particular, transcender os interesses imediatos e lutar por uma causa, o que acontece mais harmoniosamente em } \\
\text { uma democracia, em um Estado de Direito com instituições representativas. A sua queda acontece quando há } \\
\text { particularismo, individualismo, divisões e arbitrariedades. }\end{array}$ \\
\hline $\begin{array}{l}\text { Cidade } \\
\text { Mercantil }\end{array}$ & $\begin{array}{l}\text { Inspira-se na obra A riqueza das nações, de Adam Smith. O princípio superior comum é a competição e a rivalidade; } \\
\text { as grandezas são os bens desejáveis, valorosos, vendáveis e os indivíduos campeões e milionários. O que leva } \\
\text { os indivíduos à grandeza é o interesse pelas coisas, o desejo e o egoísmo - para isto eles devem ter desapego e } \\
\text { distância emocional. A evidência desta cidade ocorre com o lucro, o valor, o benefício obtido por meio da oferta de } \\
\text { mercadorias altamente cobiçadas em um mercado competitivo Sua queda se dá quando acontece a escravização ao } \\
\text { dinheiro. }\end{array}$ \\
\hline $\begin{array}{l}\text { Cidade } \\
\text { Industrial }\end{array}$ & $\begin{array}{l}\text { Baseada na obra Da fisiologia social, de Saint-Simon. Seu princípio superior comum são a eficiência e a performance. } \\
\text { A grandeza se dá pela produtividade, pela eficiência e confiabilidade, que são acessados quando se abre mão } \\
\text { da dinamicidade e do progresso, pois o mais relevante é o controle. A queda tem lugar quando a humanidade é } \\
\text { ameaçada pela instrumentalização, situação em que os indivíduos perdem sua dignidade. }\end{array}$ \\
\hline $\begin{array}{l}\text { Cidade por } \\
\text { Projetos }\end{array}$ & $\begin{array}{l}\text { Baseada em um corpus de textos de gestão da década de 1990, tem seu princípio superior comum baseado nos } \\
\text { projetos e na proliferação das redes e das conexões. A grandeza está com aqueles indivíduos empenhados, cativantes, } \\
\text { móveis, flexíveis, adaptáveis e polivalentes, principalmente com o papel de conectar indivíduos de mundos diferentes. } \\
\text { Quanto maior a capacidade de fazer elos, mais valoroso será o indivíduo. O movimento de queda acontece quando } \\
\text { há fechamento de redes, apadrinhamentos, formação de máfias e privação de elos. }\end{array}$ \\
\hline
\end{tabular}

Fonte: Adaptado de Krieger (2011), Karam (2014) e Karam e Serva (2014).

Os modelos de cidade construídos são amparados em hipóteses elaboradas a partir dos argumentos dos autores. As cidades são organizadas em ordens de grandeza, dando sustentação a várias construções de filosofia política e direcionando o senso ordinário do que é justo (BOLSTANSKI e THÉVENOT 2006). Tais hipóteses são denominadas "axiomas", os quais se encontram representadas no Quadro 2, mantendo-se a representação gráfica original apresentada por Krieger (2011).

\section{Quadro 2}

\section{Os Axiomas}

\begin{tabular}{|l|l|}
\hline \multicolumn{1}{|c|}{ Axiomas } & \multicolumn{1}{c|}{ Descrição } \\
\hline a1) Humanidade comum & $\begin{array}{l}\text { Os membros da cidade compartilham de uma humanidade comum e são capazes de alcançar } \\
\text { acordos pelas mesmas justificativas. Estas cidades reconhecem que todos os indivíduos são seres } \\
\text { humanos, e excluem construtos políticos que incorporam situações subumanas (como escravidão, } \\
\text { diferenças raciais ou de gênero). }\end{array}$ \\
\hline a2) Princípio da diferenciação & $\begin{array}{l}\text { Assume que os membros da cidade podem atingir pelo menos dois níveis diferentes de grandeza. } \\
\text { Os comportamentos adaptáveis a estas diferenças já são passíveis de formas de justificação de } \\
\text { ação e também a testes atribuídos aos estados. Este axioma preserva as particularidades de cada } \\
\text { indivíduo, ao assumir que em uma cidade possam existir tantos níveis quanto existem membros, e } \\
\text { que esses níveis são mutáveis. }\end{array}$ \\
\hline a3) Dignidade comum & $\begin{array}{l}\text { Como a cidade é formada por uma humanidade comum com estados diferenciados, por meio da } \\
\text { dignidade comum assume-se que todas as pessoas possuem poder idêntico de acessar todos os } \\
\text { estados. }\end{array}$ \\
\hline a4) Ordenação & $\begin{array}{l}\text { Os níveis nas diferentes cidades são ordenados. Essa ordenação é necessária para coordenar } \\
\text { ações e justificar distribuições, ela é expressa em uma escala de valores dos bens ou da felicidade } \\
\text { conferida a cada nível. }\end{array}$ \\
\hline
\end{tabular}


Continuação

\begin{tabular}{|l|l|}
\hline \multicolumn{1}{|c|}{ Axiomas } & \multicolumn{1}{c|}{ Descrição } \\
\hline a5) Fórmula de investimento & $\begin{array}{l}\text { Nem todos os membros de uma cidade estão nos níveis mais altos (estes são os indivíduos aos } \\
\text { quais um maior grau de felicidade é conferido, no que compete à cidade), pois os benefícios dos } \\
\text { níveis superiores estão vinculados a um custo ou a um sacrifício que é requerido para acessar } \\
\text { o estado. A forma de sacrifício é o axioma que regula a tensão entre o axioma da humanidade } \\
\text { comum e o axioma da ordenação dos estados. }\end{array}$ \\
\hline a6) Bem comum & $\begin{array}{l}\text { Este axioma possui um papel central no modelo de cidades, pois ele conecta todos os níveis em } \\
\text { um conjunto por meio de hipóteses sobre os bens e a felicidade conferida a cada estado. Ele } \\
\text { coloca a felicidade, a qual aumenta conforme uma pessoa aumenta seu nível, como sendo um } \\
\text { benefício para a cidade como um todo, isto é, como um bem comum. Quando aliado ao axioma da } \\
\text { ordenação dos estados, pode-se falar de ordem de grandeza. O bem comum é oposto ao prazer } \\
\text { autocentrado, que deve ser sacrificado para alcançar um maior estado de grandeza. No modelo } \\
\text { completo da cidade, a dignidade comum torna-se a capacidade igual dos indivíduos de alcançar o } \\
\text { bem comum. }\end{array}$ \\
\hline
\end{tabular}

Fonte: Adaptado de Krieger (2011).

Para Boltanski e Thévenot (2006), quando os acordos legítimos são gerados, não são necessários argumentos explícitos. Karam (2014) complementa que, ao assumirem um compromisso, os atores sociais não clarificam seus princípios, pois também estão inclinados ao bem comum, mesmo sem buscá-lo ativamente. Tal bem comum pode ser considerado de todos, não somente dos atores envolvidos (BOLTANSKI e THÉVENOT, 2006; KRIEGER, 2011; KARAM, 2014; KARAM e SERVA, 2014).

Contudo esta teoria da capacidade crítica não é construída apenas em pressupostos metafísicos. Boltanski e Thévenot (2006) têm interesse pela compreensão de como essas cidades são utilizadas em situações reais, concretas; ou seja, como elas são movimentadas no cotidiano das pessoas, de forma que justifique seus atos.

O acordo consolida-se em atos, em provas da realidade. Os objetos conferem solidez na intenção do plano (KARAM, 2014) e podem ser analisados como uma forma de engajamento que mostra como o reconhecimento da pessoa dotada de capacidades não se sustentará sem os aspectos que dão suporte (KARAM, 2014) e determinam a que grandeza relativa pertencem (THÉVENOT, 2001). Os regimes de justificação possibilitam o estudo da relação entre generalidades (o qual poderia traduzir como uma necessidade cognitiva) e as diversas formas de bem comum. A tensão entre coletivo e particular é inter-relacionada pela tradução de categorias sociológicas básicas, constatadas em justificações e críticas, e no aspecto em que demonstram elos entre questões cognitivas, morais e materiais (THÉVENOT, 2001; BOLTANSKI e THÉVENOT, 2006; KARAM, 2014).

Para fugir do impasse entre teoria e prática, princípios e ação, teorização e circunstâncias, Boltanski e Thevenot (2006) propõem o acesso das cidades para os mundos comuns. A teoria pragmática desconstrói esta oposição de cidade e mundos e elabora uma teoria do acordo e desacordo, a qual não corresponda apenas a uma teoria argumentativa que confronta princípios, "[...] mas que leve em conta o confronto com as circunstâncias, com a realidade, ou seja, com o engajamento de seres humanos e objetos em uma ação" (BOLTANSKI e THEVENOT, 2006, p. 163).

No processo de passagem das cidades para os mundos comuns, é necessário prestar atenção a pressupostos de caráter teórico-metodológico da Sociologia Pragmática, os quais fornecem modos esclarecedores de olhar que devem ser adotados para compreender a sociedade e que são utilizados neste trabalho. Os pressupostos elencados foram adaptados de Krieger (2011), Karam (2014) e Karam e Serva (2014):

a) Os princípios superiores comuns não formam uma lista exaustiva; desse modo, existem possibilidades para formação de outras novas cidades concretizadas tendo mundos comuns como ponto de partida.

b) Diferentes indivíduos, membros de um grupo, organização ou campo fazem referência a diversos mundos comuns. Um indivíduo, por exemplo, utiliza como justificação um princípio superior da Cidade Doméstica em suas relações familiares e um princípio superior da Cidade Industrial em seu emprego. Os fatos acontecem devido à sociedade em si ser altamente complexa, ou seja, os indivíduos possuem competências para circular em 
situações de mundos distintos.

c) Logo, um estado não é permanente e a atribuição de grandeza deve ser feita em dada situação. $O$ estado de grandeza de um indivíduo não pode ser atribuído definitivamente nas bases de suas características pessoais, para não permitir que haja a fixação permanente de um estado a uma pessoa. A prova da grandeza de uma pessoa não pode ser baseada simplesmente em uma propriedade intrínseca, pois iria pressupor uma forma prévia de equivalência já estabelecida. A prova deve ser baseada em objetos que são externos às pessoas, objetos que servirão como instrumentos ou aparelhos para determinar grandeza.

d) Todas as pessoas possuem poder de acessar os diferentes estados de valorização. Para acessar os níveis mais altos de valorização, os indivíduos devem estar dispostos a realizar investimentos, uma vez que os benefícios dos níveis superiores estão vinculados a um custo ou a um sacrifício que é requerido para acessar o estado. Ao ter seu estado de grandeza valorizado, um indivíduo age em prol do bem comum, isto é, o bem comum é oposto ao prazer autocentrado, que deve ser sacrificado para alcançar um maior estado de grandeza.

e) Para haver a possibilidade de acordos, é necessário consistência nos princípios de grandeza invocados frente aos objetos. Para tanto, faz-se mister recorrer ao framework dos mundos comuns. A consideração de uma grandeza e o teste de verificação, por envolverem o alinhamento entre os indivíduos e os objetos, nunca podem acontecer de forma teórica e, sim, por meio de transposição a uma situação prática e específica.

f) Com isso, surge a possibilidade de crítica frente às situações, gerando embate entre os mundos e entre os diferentes estados de grandeza dentro de cada cidade específica, e também de acordos entre os mundos, os quais existem pelo estabelecimento de pontes entre as diferentes cidades.

Em síntese Boltanski e Thévenot (2006, p. 29-30) explicitam:

Nenhuma situação, por mais pura que ela seja, não pode eliminar a diversidade de contingências e seus ruídos. A presença desse ruído faz pesar uma incerteza sobre as grandezas. A situação arrisca sempre de escapar e de levar a condução de uma nova prova. Na falta de um ruído exterior, prevaleceria um julgamento último que justificaria uma distribuição harmoniosa dos estados que nenhum elemento novo não remeteria em questão. Assim, o barulho do mundo, que a prova cala provisoriamente, é aquilo que o move.

Entretanto, a coordenação não se refere apenas a vários atores e diversas ações. Ela relaciona o ator com ele mesmo, em um ambiente onde ele coordena sua própria conduta (livre). É embasada na relação (ator com ele mesmo) que a comunicação conduz a outrem, não salta repentinamente para um nível de interação e seus registros. Considera-se a relação com o ambiente determinante para absorver uma conduta para guiar a si próprio partindo de certa compreensão de elementos pertinentes à situação, e ainda assegurar a apreensão da conduta de outro indivíduo. Muito mais que enfatizar totalmente o ator para caracterizar a ação, a orientação pela coordenação incita a enfatizar a maneira de compreender o ambiente do qual depende fortemente a conduta (BOLTANSKI; THÉVENOT, 2006; KARAM, 2014).

\section{REFLEXÕES FINAIS}

Pela orientação teórica da "nova" Sociologia Pragmática francesa, impressa no regime da justificação de Luc Boltanski e Laurent Thévenot, foi possível aproximar a compreensão dos fatores comportamentais dos voluntários em organizações da sociedade civil, distanciando-se da perspectiva comportamental da Psicologia. O regime da justificação correlaciona o ator social com ele mesmo, mas considera o ambiente como responsável pela coordenação do referido ator social, ou seja, o contexto da ação social realizada é que determina o comportamento do voluntário nas OSCs. Nestes espaços sociais de voluntariado, há espaços para comportamentos maquiavélicos se revelarem, tendo em vista que, pela perspectiva crítica, o comportamento subjetivo é dotado de sentido e, por conseguinte, orientado subjetivamente e motivado por ele, como afirmou Habermas (2009).

Os argumentos dispostos na "nova sociologia" pragmática francesa contribuem para afirmar que as razões para atores sociais realizarem ações não estão restritas aos fundamentos da Cidade Mercantil, mas abragem fatores comportamentais 
descritos por comportamento egoísta e subjacente à ação do voluntariado, cuja expressão real encontra-se nos impulsos e desejos inconscientes reprimidos presentes na Cidade da Fama. Na Cidade Mercantil, atuam trabalhadores que realizam trabalhos de valor e que produzem benefícios numa clara evidência de interesse pelas coisas, de satisfação de desejos e por egoísmo. Na Cidade da Fama, atuam atores que encontram nas ações de voluntariado a reputação de ser voluntário e de sucesso, pois além de permitir sua provisão, contribui para prover o outro de "coisas". A referida reputação é alcançada por meio do reconhecimento conquistado pela comunidade da qual faz parte, ou seja, da OSC que o acolheu ("aceitou") como voluntário.

Pela perspectiva teórica da Sociologia Pragmática, é possível compreender que trabalhadores e voluntários desvinculam-se pelas trocas solidárias e autogeridas que ocorrem nos espaços sociais construídos coletivamente nas OSCs. Cada voluntário contribui para que acordos sejam estabelecidos no grupo social, gerando acordos legítimos e assumindo compromissos em favor do "bem comum", um dos axiomas com papel central no modelo das cidades, por conectar todos os níveis em um conjunto mediado por "bens e felicidade", o qual se dissocia do prazer autocentrado, geralmente descrito na perspectiva freudiana.

Os fundamentos teóricos da Sociologia Pragmática evidenciam que os atores sociais autojustificam seus comportamentos por meio da realização de ações rotineiras, que se apresentam como necessidades humanas básicas, sem as quais as disputas e os conflitos seriam permanentes. Não se trata, portanto, de usar um modelo de análise dos regimes da familiaridade ou da ação planejada, mas o regime da justificação. A divisão em Cidades permite o entendimento do indivíduo como voluntário multifacetado, como se observa na ilustração da Cidade Cívica, na qual o princípio superior comum é o bem público e onde a queda ocorre quando há particularidades ou individualismos.

A corrente teórica da Sociologia Pragmática dispensa consideração pelo discurso; princípios e valores legitimadores dão sentido à ação, desligada da preocupação referente a possíveis ilusões que poderiam influenciar o ator inconscientemente (SILBER, 2003; KARAM, 2014). Assim, entende-se que a Sociologia Pragmática torna-se um instrumento teórico capaz de desvelar os sentidos dos voluntários na prática do voluntariado, justamente por não se acreditar, de acordo com a perspectiva weberiana, em ação social desprendida de uma ação orientada.

Visto que a Sociologia Pragmática ainda é pouco difundida nos Estudos Organizacionais, uma das importantes contribuições deste estudo está, sobretudo, no intuito de gerar inquietações, impulsionando debates mais aprofundados sobre o fenômeno do voluntário. 


\section{REFERÊNCIAS}

ANDION, C. Atuação das ONGs nas dinâmicas de desenvolvimento territorial sustentável no meio rural de Santa Catarina: os casos da APACO, do Centro Vianei de educação popular e da AGRECO. 2007. 427f. Tese (Doutorado em Ciências Humanas) - Universidade Federal de Santa Catarina, Florianópolis, 2007.

BARTHE, Y. et al. Sociologia pragmática: guia do usuário. Sociologias, Porto Alegre, v. 18, n. 41, p. 84-129, jan./abr., 2016.

BERGERET, J. A personalidade normal e patológica. Porto Alegre: Artes Médicas, 1988.

BOLTANSKI, L.; CHIAPELLO, E. O novo espírito do capitalismo. Tradução: Ivone C. Benedetti. São Paulo: WMF Martins Fontes, 2009.

BOLTANSKI, L.; THÉVENOT, L. On justification: economies of worth. Tradução: Catherine Porter. New Jersey: Princeton University, 2006. [Edição original: 1991]

CHARITIES Aid Foundation. World giving index 2012: a global view of giving trends. December, 2012. Disponível em: <http://www.cafonline. org/pdf/worldgivingindex2012web.pdf>. Acesso em: 15 ago. 2014.

CONSTANTINO, R. Egoísmo racional: o individualismo de Ayn Rand. Rio de Janeiro: Documenta Histórica, 2007.

CORREA, D. S.; DIAS, R. C. A crítica e os momentos críticos: de la justification e a guinada pragmática na sociologia francesa. Mana, Rio de Janeiro, v. 22, n. 1, p. 67-99, Apr. 2016.

DOHME, V. Voluntariado: equipes produtivas: como liderar ou fazer parte de uma delas. São Paulo: Mackenzie, 2001.

ESCOBAR, J. J.; GUTIERREZ, A. C. M. Tercer sector y univocidad conceptual: necesidad y elementos configuradores. Revista Katálysis, v. 11, n. 1, p. 84-95, jun. 2008.

FREUD, S. Obras completas de Sigmund Freud: o futuro de uma ilusão. O mal-estar na civilização. Rio de Janeiro: Imago, 1974.

FOUCAULT, M. Microfísica do poder. São Paulo: Graal, 2012.

GAULEJAC, V. Gestão como doença social: ideologia, poder gerencialista e fragmentação social. São Paulo: Idéias e Letras, 2007.

GUESSER, A. H. A etnometodologia e a análise da conversação e da fala. Em Tese, v. 1, n. 1, p. 149-168, ago./dez. 2003.

HABERMAS, J. Para a reconstrução do materialismo histórico. Desenvolvimento da moral e identidade do eu (Texto original de 1974-6). São Paulo: Brasiliense, 1990. p. 49-73.

HABERMAS, J. Teoría de la acción comunicativa. Madrid: Taurus Humanidades, 1999.

HABERMAS, J. A crise de legitimação no capitalismo tardio. Rio de Janeiro: Tempo Brasileiro, 2009.

HATTORI, W. T.; YAMAMOTO, M. E. Evolução do comportamento humano: Psicologia evolucionista. Estudos de Biologia, Ambiente Diversificado, v. 34, n. 83, p. 101-112, 2012.

HERITAGE, J. C. Etnometodogia. In: GIDDENS, A.; TURNER, J. (orgs.). Teoria social hoje. 1. reimpressão, São Paulo: Unesp, 1999. p. 321-392.
IBGE. Instituto Brasileiro de Geografia e Estatística. As fundações privadas e associações sem fins lucrativas no Brasil 2010. Estudos e Pesquisas Informação Econômica, n. 20, Rio de Janeiro, 2012. Disponível em: <ftp://ftp.ibge.gov.br/Fundacoes_Privadas_e_ Associacoes/2010/fasfil.pdf>. Acesso em: 23 out. 2017.

KANAANE, R. Comportamento humano: o homem rumo ao século XXI. São Paulo: Atlas, 1994.

KARAM, C. A. Legitimando uma inovação social: o caso do Corpo de Bombeiros Voluntários de Joinville. 2014. 404f. Tese (Doutorado em Administração) - Universidade Federal de Santa Catarina, Florianópolis, 2014.

KARAM, C. A.; SERVA, M. Pesquisando inovações sociais à luz da Sociologia Pragmática: uma nova proposta de abordagem. Revista Red de Posgrados de Investigación Latinos en Administración y Estudios Organizacionales, PILARES. México: 2014.

KOLB, L. C. Psiquiatria clínica. Rio de Janeiro: Interamericana, 1977.

KRIEGER, M. Legitimidade das Organizações da Sociedade Civil na Região Sul do Brasil: uma análise da percepção dos atores do campo à luz da Sociologia Pragmática. 2011. 254 f. Dissertação (Mestrado) - Universidade do Estado de Santa Catarina, Florianópolis, 2011.

LEWIN, K. Princípios de psicologia topológica. São Paulo: Cultrix, 1973.

MACHADO, L. M. V. Atores sociais: movimentos urbanos, continuidade e gênero. São Paulo: Annablume, 1995.

MAQUIAVEL, N. O príncipe. Porto Alegre: L\&PM, 1999.

MONTAÑO, C. Terceiro setor e questão social: crítica ao padrão emergente de intervenção social. São Paulo: Cortez, 2005.

MORGAN, G. Imagens da organização. São Paulo: Atlas, 2013.

MORIN, E. M. Os sentidos do trabalho. Revista de Administração de Empresas, v. 41, n. 3, p. 8-19, jul./set. 2001.

MOSCOVICI, F. Renascença organizacional: a revalorização do homem frente à tecnologia para o sucesso da nova empresa. Rio de Janeiro: José Olympio, 2012.

ONU BRASIL. Nações Unidas no Brasil. A ONU e o voluntariado. Disponível em: <https://nacoesunidas.org/vagas/voluntariado/>. Acesso em: 23 out. 2017.

SARAIVA, L. A. S. Além do senso comum sobre o terceiro setor: uma provocação. In: PIMENTA, S. M.; SARAIVA, L. A. S.; CORREA, M. L. (Org.). Terceiro setor: dilemas e polêmicas. São Paulo: Saraiva, 2006. Capítulo 2.

SCHUTZ, W. C. Psicoterapia pelo encontro. São Paulo: Atlas, 1978.

SILBER, I. Pragmatic sociology as cultural sociology. Beyond repertoire theory? European Journal of Social Theory, v. 6, n. 4, p. 427-449, 2003.

TENÓRIO, F. G. Gestão de ONGs: principais funções gerenciais. São Paulo: FGV, 2001.

TENÓRIO, F. G. Um espectro ronda o terceiro setor, o espectro do mercado: ensaios de gestão social. ljuí: Unijuí: 2004. 
Contradições no agir do voluntário nas organizações da sociedade civil: ensaio teórico à luz da sociologia pragmática francesa
Tandara Dias Gonçalves | Denize Grzybovski Anelise Rebelato Mozzato | Carlisa Smoktunowicz Toebe
TENÓRIO, F. G. Tem razão a gestão social? In: COLÓQUIO INTERNACIONAL EPISTEMOLOGIA E SOCIOLOGIA DA CIÊNCIA DA ADMINISTRAÇÃO, 3., 2013, Florianópolis. Anais Eletrônicos... Florianópolis: Rede ORD/ UFSC, 2013. Disponível em: <http://www.coloquioepistemologia.com. br/anais2013/ANE103.pdf>. Acesso em: 31 mar. 2014.

THÉVENOT, L. Pragmatiques de la connaissance. In: BORZEIX, A.; BOUVIER, A.; PHARO, P. (sous la dir. de). Sociologie et connaissance: nouvelles approches cognitives. Paris: CNRS, 1998. p. 101-139.
THÉVENOT, L. Pragmatic regimes governing the engagement with the world. In: KNORR-CETINA, K.; SCHATZKI, T.; SAVIGNY EIKE, V. (Eds.). The practice turn in contemporary theory. London: Routledge. p. 56-73, 2001.

TOURAINE, A. Após a crise: a decomposição da vida social e o surgimento de atores não sociais. Petrópolis: Vozes, 2011.

VANDENBERGHE, F. Construção e crítica na nova sociologia francesa. Sociedade e Estado, v. 21, n. 2, p. 315-366, mai./ago 2006.

Tandara Dias Gonçalves

Mestre em Desenvolvimento pela Universidade Regional do Noroeste do Estado do Rio Grande do Sul (Unijuí); Secretária Executiva Bilíngue. ljuí - RS, Brasil. E-mail: tandara_goncalves@hotmail.com

Denize Grzybovski

Doutora em Administração pela Universidade Federal de Lavras (UFLA); Professora titular no Programa de Pós-Graduação em Administração pela Universidade de Passo Fundo (PPGAdm/UPF), Passo Fundo, RS, Brasil; Professora convidada no Programa de Pós-Graduação em Desenvolvimento Regional na Universidade Regional do Noroeste do Estado do Rio Grande do Sul (PPGDR/Unijuí), ljuí - RS, Brasil. E-mail: gdenize@upf.br

Anelise Rebelato Mozzato

Doutora em Administração pela Universidade do Vale do Rio dos Sinos (Unisinos); Professora titular no Programa de Pós-Graduação em Administração na Universidade de Passo Fundo (PPGAdm/UPF), Passo Fundo - RS, Brasil. E-mail: anerebe@upf.br

Carlisa Smoktunowicz Toebe

Mestre em Desenvolvimento Regional pela Universidade Regional do Noroeste do Estado do Rio Grande do Sul (Unijuí); Professora no Instituto Federal de Educação, Ciência e Tecnologia do Rio Grande do Sul (IFRS - Campus Sertão), Sertão - RS, Brasil. E-mail: carlisa.toebe@sertao.ifrs.edu.br 